\title{
Platelet-Rich Plasma Augmentation of Arthroscopic Rotator Cuff Repair Lowers Retear Rates and Improves Short-Term Postoperative Functional Outcome Scores: A Systematic Review of Meta-Analyses
}

\author{
Zafar Ahmad, M.D., Swee Ang, M.D., Neil Rushton, M.D., Adrian Harvey, M.D., \\ Kash Akhtar, Sebastian Dawson-Bowling, M.D., and Ali Noorani, M.D.
}

\begin{abstract}
Purpose: The purpose of this study is to conduct a systematic review of meta-analyses of rotator cuff repair using platelet-rich plasma (PRP) to identify whether PRP improves clinical function and rate of tendon retears. We will (1) conduct a systematic review of the current meta-analyses of rotator cuff repair using platelet-rich plasma available in the literature, (2) evaluate the quality of these meta-analyses using the Preferred Reporting Items for Systematic Review (PRISMA) methodology, (3) identify whether PRP improves clinical function and rate of tendon retears, and develop guidance to improve future studies in this area. Methods: We carried out a systematic review of previous meta-analyses published on the clinical outcomes of PRP used in the treatment of rotator cuff tears. We performed a comprehensive search of PubMed, Medline, Cochrane, CINAHL (Cumulative Index to Nursing and Allied Health Literature), and Embase databases, using various combinations of the commercial names of each PRP preparation and "rotator cuff" (with its associated terms), looking specifically at human meta-analysis studies involving the repair of the rotator cuff tendon surgically in the English language. Data validity was assessed and collected on clinical outcomes. Following this, a meta-analysis was undertaken. Results: Thirteen meta-analyses met the inclusion and exclusion criteria. All were considered of similar quality with Oxman-Guyatt index of 9 and PRISMA score of more than 24. A total of 1,800 patients with an average follow up of 12 to 36 months. The use of PRP for arthroscopic rotator cuff tear, when compared with controls, leads to a lower number of retears, improved short-term postoperative scores, and functional outcome. The following postoperative scores were reported: Constant: 12, Simple Shoulder Test: 10, ASES (American Shoulder and Elbow Surgeons): 9, UCLA (University of California, Los Angeles) 1 1, SANE (Single Assessment Numeric Evaluation) 1, VAS (visual analog scale): 6, and Retears: 13. Subgroup analysis showed that leukocyte content and gel application make no difference in the effectiveness of PRP. VAS score subgroup analysis showed short-term pain relief. Conclusions: Our study shows that PRP is effective in reducing retears after rotator cuff repair and improving functional outcome scores and reducing short-term pain. Level of Evidence: Level III, systematic review of Level I-III studies.
\end{abstract}

\section{Introduction}

$\mathbf{T}$ he number of rotator cuff repairs continues to increase with overall satisfactory results, but the

From the Barts Health NHS Trust, London, United Kingdom.

The authors report the following potential conflicts of interest or sources of funding: Supported by charitable grants of Charnlee Latta trust and the Winston Churchill Memorial Trust. Full ICMJE author disclosure forms are available for this article online, as supplementary material.

Received April 4, 2020; accepted December 12, 2021.

Address correspondence to Zafar Ahmad, M.D., Barts Health NHS Trust, Royal London, Whitechapel Road, E1 1BB, London, United Kingdom. E-mail:ziaxj@hotmail.com

(C) 2022 THE AUTHORS. Published by Elsevier Inc. on behalf of the Arthroscopy Association of North America. This is an open access article under the CC BY-NC-ND license (http://creativecommons.org/licenses/by-nc-nd/4.0/). 2666-061X/20406

https://doi.org/10.1016/j.asmr.2021.12.012 number of reported retears is still significant. ${ }^{1}$ Factors that may affect outcomes include those related to the surgeon, the surgery, and the patient. Surgeon factors include the amount of experience a surgeon has, which shows a correlation with lower retear rates. ${ }^{2}$ Surgical factors include the nature of the tear and the method of repair. Patient factors include the age, comorbidities, and quality of the remnant tissue. ${ }^{1}$ The tissue is often of poor quality in larger chronic tears, and when repaired, the remnant tissue heals with scar tissue, forming a weaker biomechanical structure. ${ }^{2}$ The normal healing of tendon heals with scar tissue, which is an inferior construct compared with normal tissue. ${ }^{3}$ Biological augmentation using methods such as platelet-rich plasma (PRP) has the potential to enhance tissue healing for tendon repairs. It can either lead to 
enhanced tissue repair, improving the scar tissue strength, or ultimately, it could lead to tissue regeneration that has the potential to heal tears with highquality tendon tissue. ${ }^{4,5}$

Platelet-rich plasma is an autologous blood-derived concentrate of plasma, which has a high amount of growth factors. The initial research showed little promise; however, a number of later studies, including meta-analyses, have shown a reduction of retear rates in rotator cuff repair. ${ }^{4}$ This suggests with adequate power an effect can be detected. It stands to reason that an analysis of all the current potential meta-analyses may reveal trends not identified in individual studies.

The purpose of this study is to conduct a systematic review of meta-analyses of rotator cuff repair using PRP to identify whether PRP improves clinical function and rate of tendon retears. These include (1) to conduct a systematic review of the current meta-analyses of rotator cuff repair using platelet-rich plasma available in the literature, (2) to evaluate the quality of these metaanalyses using the Preferred Reporting Items for Systematic Review (PRISMA) methodology, (3) to identify whether PRP improves clinical function and rate of tendon retears, (4) and to develop guidance to improve future studies in this area. We hypothesize that PRP does improve clinical outcomes and reduces retears for rotator cuff repair.

\section{Methods}

This study is a level III systematic review of previous meta-analyses. This systematic review was performed in line with the PRISMA (Preferred Reporting Items for Systematic Reviews and Meta-Analyses) statement.

\section{Search Strategy}

We performed a comprehensive search of PubMed, Medline, Cochrane, CINAHL (Cumulative Index to Nursing and Allied Health Literature), and Embase databases for the years 1966 to Jan 1, 2020. To minimize the number of articles that may be missed, we used various combinations of the commercial names (Smartprep, Cascade, Harvest, GPS, etc.) of each PRP preparation and the following key words: tendon, rotator cuff, supraspinatus, infraspinatus, platelet, platelet-rich plasma, PRP, "shoulder", "subscapularis", "external rotators", "systematic review", "meta-analysis", and platelet concentrate (see Appendix 1). All articles relevant to the subject were retrieved, and their bibliographies were searched for further references in the context of the use of orthobiologics in the treatment of rotator cuff tears. We identified 180 citations from the initial electronic searches looking at published meta-analyses. These were then streamlined to only include surgical repair of rotator cuff tendons augmented with PRP.

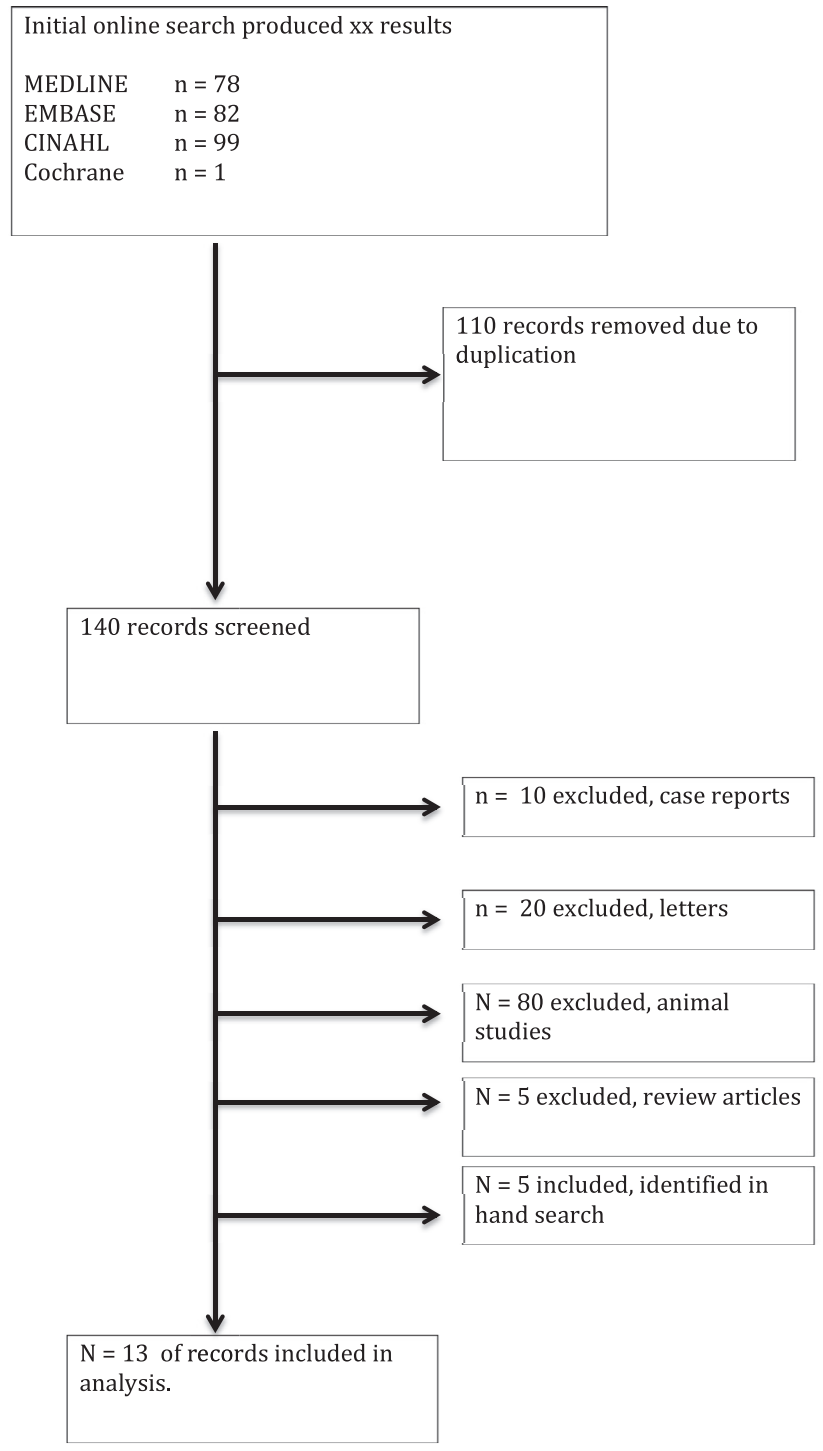

Fig 1. Search strategy.

\section{Eligibility Criteria}

The search was limited to meta-analysis articles published in peer-reviewed journals and the English language without date restrictions up to Jan 1, 2020 (Fig 1). Case reports, literature reviews, abstract-only publications, and letters to the editors were all excluded. Animal studies were not included. Studies were included if they reported on clinical outcomes of PRP augmentation in patients with surgical repair of rotator cuff tears and were meta-analyses or systematic reviews. All types of tears were included. All types of PRP preparations and applications were included. No limit was set for minimum follow-up duration.

\section{Extraction of Data}

Data were extracted from all eligible articles restricted to meta-analyses. Each study was reviewed for the quality of its methodology, and differences were 
Table 1A. List of Meta-Analysis: Summary of Articles with Number of Articles Analyzed and the Article Citation

\begin{tabular}{|c|c|c|c|c|c|c|c|}
\hline First Author & Journal & $\begin{array}{c}\text { Date of } \\
\text { Publication }\end{array}$ & $\begin{array}{c}\text { Date of } \\
\text { Last Literature } \\
\text { Search }\end{array}$ & $\begin{array}{l}\text { Level of } \\
\text { Evidence }\end{array}$ & $\begin{array}{l}\text { No. of } \\
\text { articles } \\
\text { reviewed }\end{array}$ & $\begin{array}{l}\text { No of systematic } \\
\text { reviews/ } \\
\text { Meta-analysis to cite }\end{array}$ & $\begin{array}{l}\text { No of systematic } \\
\text { reviews/ } \\
\text { Meta-analysis cited }\end{array}$ \\
\hline$\overline{\text { Chahal }}$ & Arthroscopy & Nov 2012 & December 2011 & 3 & 5 & 0 & 0 \\
\hline Zhang & PLos One & July 2013 & April 2013 & 2 & 7 & 1 & 1 \\
\hline Moraes & Cochrane & April 2014 & March 2013 & 2 & 3 & 1 & 1 \\
\hline $\mathrm{Li}$ & Arthroscopy & November 2014 & May 2013 & 2 & 7 & 1 & 1 \\
\hline Zhao & Arthroscopy & January 2015 & September 2013 & 2 & 8 & 2 & 2 \\
\hline Warth & Arthroscopy & February 2015 & September 2013 & 2 & 11 & 2 & 0 \\
\hline Vavken & AJSM & March 2015 & August 2014 & 2 & 13 & 3 & 1 \\
\hline Cai & JSES & December 2015 & January 2015 & 1 & 8 & 4 & 0 \\
\hline Yang & $\begin{array}{c}\text { Journal of Sports Medicine } \\
\text { and Physical Fitness }\end{array}$ & November 2016 & Not stated & 1 & 8 & 5 & 1 \\
\hline $\mathrm{Fu}$ & Clinical Rehabilitation & February 2017 & December 2015 & 1 & 11 & 6 & 4 \\
\hline Han & $\begin{array}{l}\text { Journal of Orthopaedic } \\
\text { Surgery and Research }\end{array}$ & June 2019 & September 2016 & 1 & 13 & 7 & 6 \\
\hline Hurley & AJSM & March 2019 & March 2017 & 1 & 18 & 8 & 7 \\
\hline Chen & $A J S M$ & November 2019 & December 2017 & 1 & 18 & 9 & 7 \\
\hline
\end{tabular}

resolved by discussion among the authors. A descriptive summary of the results is presented. A total of 13 articles met the inclusion criteria (Table 1). If data were missing, the authors of the articles were contacted to determine whether those potential data were available.

The characteristics of the meta-analyses are demonstrated in Tables 1-6. The data points evaluating effect size and mean differences between these points were extracted. The number of retears, patient function, and pain score were analyzed and compared. Methodologies of each study were compared.

The QUOROM (QUality Of Reporting Of Metaanalysis) used previously by Saltzman et al. ${ }^{6}$ has been superseded by PRISMA. ${ }^{7}$ The PRISMA (Preferred Reporting Items for Systematic reviews and Metaanalyses) is a 27-item checklist that is used to evaluate the quality of reporting. New items included are an evaluation of objective, presence of protocol, a full description of electronic search, outcome level of assessment, risk of bias, limitations, and sources of funding. The meta-analysis was further assessed by the Oxman-Guyatt ${ }^{8}$ score as a quality appraisal tool. This is a 10-point questionnaire looking at the search method, criteria of included studies, the bias in selection, the validity of the studies, and whether the results supported the conclusion the authors had undertaken. The Oxman-Guyatt score provides an opportunity for subjective feedback, which the PRISMA method is lacking. The Jadad decision algorithm ${ }^{9}$ was used to evaluate discordant reviews. Two authors independently applied the search method and the evaluation of the scoring system to analyze these studies.

\section{Results}

Thirteen studies met the criteria (Table 1). The range of date of publications was from November 2012 to November 2019. Publications were published in a number of journals, including Arthroscopy, American Journal of Sports Medicine, Journal of Shoulder and Elbow Surgeons, and PLoS One. The earliest study was

Table 1B. Summary of Conclusion of Meta-Analysis and Risk of Bias

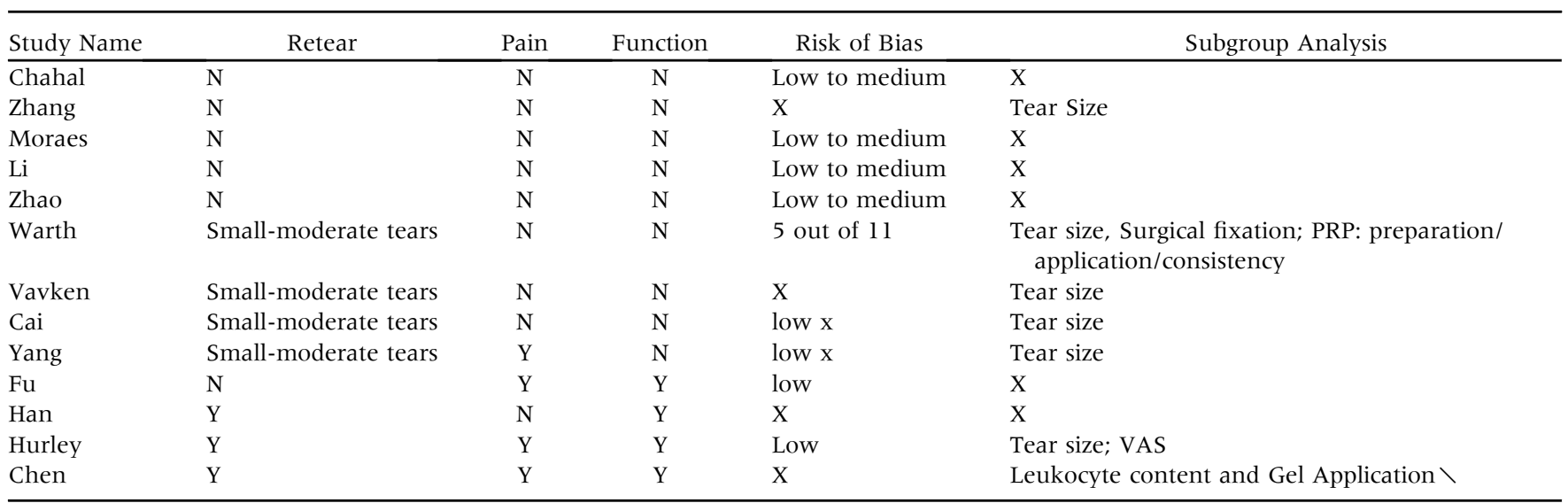

\footnotetext{
$\mathrm{N}$, not effective; Y, effective.
} 
Table 2. Scores Used in Meta-Analysis

\begin{tabular}{|c|c|c|c|c|c|c|c|c|c|c|c|c|c|}
\hline & Chahal & Zhang & Moraes & $\mathrm{Li}$ & Zhao & Warth & Vavken & Cai & Yang & $\mathrm{Fu}$ & Han & Hurley & Chen \\
\hline \multicolumn{14}{|l|}{ 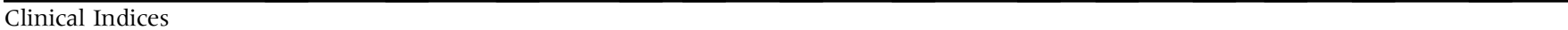 } \\
\hline Constant score & $\mathrm{Y}$ & $\mathrm{Y}$ & $\mathrm{Y}$ & $\mathrm{Y}$ & $\mathrm{Y}$ & $\mathrm{Y}$ & $\mathrm{N}$ & Y & $\mathrm{Y}$ & $\mathrm{Y}$ & $\mathrm{Y}$ & $\mathrm{Y}$ & $\mathrm{Y}$ \\
\hline SST score & $\mathrm{Y}$ & Y & $\mathrm{Y}$ & $\mathrm{Y}$ & $\mathrm{N}$ & $\mathrm{Y}$ & $\mathrm{N}$ & Y & $\mathrm{Y}$ & $\mathrm{Y}$ & $\mathrm{Y}$ & $\mathrm{N}$ & $\mathrm{Y}$ \\
\hline UCLA Shoulder score & $\mathrm{Y}$ & Y & $\mathrm{Y}$ & $\mathrm{Y}$ & $\mathrm{N}$ & $\mathrm{Y}$ & $\mathrm{N}$ & $\mathrm{Y}$ & $\mathrm{Y}$ & $\mathrm{Y}$ & $\mathrm{Y}$ & Y & $\mathrm{Y}$ \\
\hline SANE score & $\mathrm{Y}$ & $\mathrm{N}$ & $\mathrm{N}$ & $\mathrm{N}$ & $\mathrm{N}$ & $\mathrm{N}$ & $\mathrm{N}$ & $\mathrm{N}$ & $\mathrm{N}$ & $\mathrm{N}$ & $\mathrm{N}$ & $\mathrm{N}$ & $\mathrm{N}$ \\
\hline Overall Function & $\mathrm{N}$ & $\mathrm{N}$ & $\mathrm{Y}$ & $\mathrm{N}$ & $\mathrm{N}$ & $\mathrm{N}$ & $\mathrm{N}$ & $\mathrm{N}$ & $\mathrm{N}$ & $\mathrm{Y}$ & $\mathrm{N}$ & $\mathrm{N}$ & $\mathrm{N}$ \\
\hline $\begin{array}{l}\text { Constant Pain Score } \\
\text { Complications }\end{array}$ & $\mathrm{N}$ & $\mathrm{N}$ & $\mathrm{N}$ & $\mathrm{N}$ & $\mathrm{N}$ & $\mathrm{N}$ & $\mathrm{N}$ & $\mathrm{N}$ & $\mathrm{N}$ & $\mathrm{Y}$ & $\mathrm{N}$ & $\mathrm{N}$ & $\mathrm{N}$ \\
\hline Retear rate (MRI) & $\mathrm{Y}$ & Y & $\mathrm{Y}$ & $\mathrm{Y}$ & Y & Y & Y & $\mathrm{Y}$ & $\mathrm{Y}$ & $\mathrm{Y}$ & $\mathrm{Y}$ & Y & $\mathrm{Y}$ \\
\hline Revision surgery & $\mathrm{N}$ & $\mathrm{N}$ & $\mathrm{N}$ & $\mathrm{N}$ & Y & $\mathrm{N}$ & $\mathrm{Y}$ & $\mathrm{N}$ & $\mathrm{N}$ & $\mathrm{N}$ & $\mathrm{N}$ & $\mathrm{N}$ & $\mathrm{N}$ \\
\hline Overall complications & $\mathrm{N}$ & $\mathrm{N}$ & $\mathrm{N}$ & $\mathrm{N}$ & $\mathrm{N}$ & $\mathrm{N}$ & $\mathrm{Y}$ & $\mathrm{N}$ & $\mathrm{N}$ & $\mathrm{N}$ & $\mathrm{N}$ & $\mathrm{N}$ & $\mathrm{N}$ \\
\hline
\end{tabular}

published by Chahal et al. ${ }^{10}$ in Arthroscopy that reviewed 5 studies; however, it did not include only randomized controlled trials. This is in contrast to Chen et al., ${ }^{11}$ who published in November 2019 and reviewed 18 studies, which were all level I randomized controlled trials. The majority of articles cited previous meta-analyses.

The mean age of the patients in the studies ranged from 58 to 62 , with a range reported from 28 to 79 . Initial studies suggested that PRP did not affect the clinical and radiological outcomes. ${ }^{10,12,13,14,15}$ Radiological outcomes were all measured using MRI on all follow-up patients as standard procedure. However, later studies used a subgroup analysis and noted a reduced retear rate in the repair of small and medium tears with PRP. Warth et al. ${ }^{13}$ noted that injecting PRP between the tendon-bone interface improved outcomes. ${ }^{16}$ With the increasing amount of patient data, later meta-analyses were able to detect reduced retear, improved pain, and functional outcome in all types of tears. This suggests that the earlier studies were inadequately powered to note this difference.

\section{Data Collection}

All of the meta-analyses collected retear rates (see Table 2). Only the Vavken et al. ${ }^{16}$ looked at complications of surgery. Both Vavken et al. ${ }^{16}$ and Zhao et al. ${ }^{17}$ looked at the topic of revision surgery. Only 7 studies looked at the VAS pain score. The timing of these scores was vastly different from some studies looking at 1month postoperation and others looking further ahead at 6 months or more. The clinical indices analyzed were different. The majority of articles looked at the Constant score. However, early articles, like Chahal et al. in 2012, ${ }^{10}$ looked at 5 different scores, whereas Zhao et al. ${ }^{17}$ in 2015 only looked at the Constant score. Vavken et al. in $2014^{16}$ looked at no clinical indices. Fortunately, the later articles, including Han et al., ${ }^{18}$ Hurley et al., ${ }^{19}$ and Chen et al. ${ }^{11}$ analyzed the majority of clinical scoring.

\section{Quality of Search}

The majority of articles searched were found in PUBMED, EMBASE, and the Cochrane library (Table 3). Only Vavken et al. ${ }^{16}$ was quoted as using

Table 3. Database Analyzed

\begin{tabular}{|c|c|c|c|c|c|c|c|c|c|}
\hline Article & PubMed & EMBASE & $\begin{array}{c}\text { Cochrane Library of } \\
\text { Databases }\end{array}$ & CINAHL & LILACS & BIOSIS & Ovid & No of primary studies & $\begin{array}{l}\text { Primary Studies Included } \\
\text { Only RCTS or Quasi-RCTS }\end{array}$ \\
\hline Chahal & $\mathrm{Y}$ & $\mathrm{Y}$ & $\mathrm{Y}$ & $\mathrm{N}$ & $\mathrm{N}$ & $\mathrm{N}$ & $\mathrm{N}$ & 5 & $\mathrm{~N}$ \\
\hline Zhang & Y & Y & $\mathrm{Y}$ & $\mathrm{N}$ & $\mathrm{N}$ & $\mathrm{N}$ & $\mathrm{N}$ & 7 & $\mathrm{~N}$ \\
\hline $\mathrm{Li}$ & $\mathrm{Y}$ & $\mathrm{Y}$ & $\mathrm{Y}$ & $\mathrm{N}$ & $\mathrm{N}$ & Y & $\mathrm{Y}$ & 7 & $\mathrm{Y}$ \\
\hline Zhao & Y & $\mathrm{Y}$ & $\mathrm{Y}$ & $\mathrm{N}$ & $\mathrm{N}$ & $\mathrm{N}$ & $\mathrm{N}$ & 8 & $\mathrm{Y}$ \\
\hline Warth & Y & Y & $\mathrm{N}$ & $\mathrm{N}$ & $\mathrm{N}$ & $\mathrm{N}$ & $\mathrm{N}$ & 11 & $\mathrm{~N}$ \\
\hline Yang & Y & $\mathrm{Y}$ & Y & $\mathrm{N}$ & $\mathrm{N}$ & $\mathrm{N}$ & $\mathrm{N}$ & 8 & $\mathrm{Y}$ \\
\hline $\mathrm{Fu}$ & Y & $\mathrm{Y}$ & Y & $\mathrm{N}$ & $\mathrm{N}$ & $\mathrm{N}$ & $\mathrm{Y}$ & 11 & Y \\
\hline Han & Y & $\mathrm{Y}$ & Y & $\mathrm{N}$ & $\mathrm{N}$ & $\mathrm{N}$ & $\mathrm{N}$ & 13 & Y \\
\hline Hurley & Y & $\mathrm{Y}$ & Y & $\mathrm{N}$ & $\mathrm{N}$ & $\mathrm{N}$ & $\mathrm{N}$ & 18 & Y \\
\hline Chen & Y & $\mathrm{N}$ & $\mathrm{Y}$ & $\mathrm{N}$ & $\mathrm{N}$ & $\mathrm{N}$ & $\mathrm{Y}$ & 18 & Y \\
\hline
\end{tabular}


Table 4. Studies Included

\begin{tabular}{|c|c|c|c|c|c|c|c|c|c|c|c|c|c|}
\hline Primary Study & Chahal 2012 & Zhang 2013 & Moraes 2014 & Li 2014 & Zhao 2015 & Warth 2015 & Vavken 2015 & Cai 2015 & Yang 2016 & Fu 2017 & Han 2019 & Hurley 2019 & Chen 2019 \\
\hline Castricini 2010 & $\mathrm{Y}$ & $\mathrm{Y}$ & $\mathrm{Y}$ & $\mathrm{Y}$ & $\mathrm{Y}$ & $\mathrm{Y}$ & $\mathrm{Y}$ & $\mathrm{Y}$ & $\mathrm{Y}$ & $\mathrm{Y}$ & $\mathrm{N}$ & $\mathrm{Y}$ & $\mathrm{Y}$ \\
\hline Randelli 2011 & $\mathrm{Y}$ & $\mathrm{Y}$ & $\mathrm{Y}$ & $\mathrm{Y}$ & $\mathrm{Y}$ & $\mathrm{Y}$ & $\mathrm{Y}$ & $\mathrm{Y}$ & $\mathrm{Y}$ & $\mathrm{Y}$ & $\mathrm{N}$ & $\mathrm{Y}$ & $\mathrm{Y}$ \\
\hline Barber 2011 & $\mathrm{Y}$ & $\mathrm{N}$ & $\mathrm{N}$ & $\mathrm{N}$ & $\mathrm{N}$ & $\mathrm{N}$ & $\mathrm{Y}$ & $\mathrm{N}$ & $\mathrm{N}$ & $\mathrm{N}$ & $\mathrm{N}$ & $\mathrm{N}$ & $\mathrm{N}$ \\
\hline Buford 2011 & $\mathrm{~N}$ & $\mathrm{~N}$ & $\mathrm{~N}$ & $\mathrm{~N}$ & $\mathrm{~N}$ & $\mathrm{~N}$ & $\mathrm{Y}$ & $\mathrm{N}$ & $\mathrm{N}$ & $\mathrm{N}$ & $\mathrm{N}$ & $\mathrm{N}$ & $\mathrm{N}$ \\
\hline Longo 2011 & $\mathrm{~N}$ & $\mathrm{~N}$ & $\mathrm{~N}$ & $\mathrm{~N}$ & $\mathrm{~N}$ & $\mathrm{~N}$ & $\mathrm{Y}$ & $\mathrm{N}$ & $\mathrm{N}$ & $\mathrm{N}$ & $\mathrm{N}$ & $\mathrm{N}$ & $\mathrm{N}$ \\
\hline Bergeson 2012 & $\mathrm{Y}$ & $\mathrm{N}$ & $\mathrm{N}$ & $\mathrm{N}$ & $\mathrm{N}$ & $\mathrm{N}$ & $\mathrm{Y}$ & $\mathrm{N}$ & $\mathrm{N}$ & $\mathrm{N}$ & $\mathrm{N}$ & $\mathrm{N}$ & $\mathrm{N}$ \\
\hline Jo 2011 & $\mathrm{Y}$ & $\mathrm{Y}$ & $\mathrm{N}$ & $\mathrm{N}$ & $\mathrm{N}$ & $\mathrm{Y}$ & $\mathrm{Y}$ & $\mathrm{Y}$ & $\mathrm{N}$ & $\mathrm{N}$ & $\mathrm{N}$ & $\mathrm{N}$ & $\mathrm{N}$ \\
\hline Gumina 2012 & $\mathrm{~N}$ & $\mathrm{Y}$ & $\mathrm{Y}$ & $\mathrm{Y}$ & $\mathrm{Y}$ & $\mathrm{Y}$ & N/A & $\mathrm{N}$ & $\mathrm{Y}$ & $\mathrm{Y}$ & $\mathrm{N}$ & $\mathrm{Y}$ & $\mathrm{Y}$ \\
\hline Weber 2013 & $\mathrm{~N}$ & $\mathrm{Y}$ & $\mathrm{N}$ & $\mathrm{Y}$ & $\mathrm{Y}$ & $\mathrm{Y}$ & $\mathrm{Y}$ & $\mathrm{Y}$ & $\mathrm{Y}$ & $\mathrm{N}$ & $\mathrm{N}$ & $\mathrm{Y}$ & $\mathrm{Y}$ \\
\hline Antuna 2013 & $\mathrm{~N}$ & $\mathrm{Y}$ & $\mathrm{Y}$ & $\mathrm{Y}$ & $\mathrm{N}$ & $\mathrm{Y}$ & N/A & $\mathrm{N}$ & $\mathrm{Y}$ & $\mathrm{N}$ & $\mathrm{N}$ & $\mathrm{N}$ & $\mathrm{N}$ \\
\hline Jo 2013 & $\mathrm{~N}$ & $\mathrm{~N}$ & $\mathrm{~N}$ & $\mathrm{~N}$ & $\mathrm{Y}$ & $\mathrm{Y}$ & N/A & $\mathrm{N}$ & $\mathrm{N}$ & $\mathrm{N}$ & $\mathrm{N}$ & $\mathrm{Y}$ & $\mathrm{Y}$ \\
\hline Ruiz-Moneo 2013 & $\mathrm{~N}$ & $\mathrm{~N}$ & $\mathrm{~N}$ & $\mathrm{Y}$ & $\mathrm{Y}$ & $\mathrm{Y}$ & N/A & $\mathrm{N}$ & $\mathrm{Y}$ & $\mathrm{Y}$ & $\mathrm{N}$ & $\mathrm{Y}$ & $\mathrm{Y}$ \\
\hline Malavolta 2014 & $\mathrm{~N}$ & $\mathrm{~N}$ & $\mathrm{Y}$ & $\mathrm{N}$ & $\mathrm{N}$ & $\mathrm{Y}$ & N/A & $\mathrm{Y}$ & $\mathrm{Y}$ & $\mathrm{Y}$ & $\mathrm{N}$ & $\mathrm{Y}$ & $\mathrm{Y}$ \\
\hline Sanchez 2011 & $\mathrm{~N}$ & $\mathrm{~N}$ & $\mathrm{~N}$ & $\mathrm{~N}$ & $\mathrm{Y}$ & $\mathrm{Y}$ & N/A & $\mathrm{N}$ & $\mathrm{N}$ & $\mathrm{N}$ & $\mathrm{N}$ & $\mathrm{Y}$ & $\mathrm{N}$ \\
\hline Rodeo 2012 & $\mathrm{~N}$ & $\mathrm{Y}$ & $\mathrm{Y}$ & $\mathrm{Y}$ & $\mathrm{Y}$ & $\mathrm{Y}$ & N/A & $\mathrm{N}$ & $\mathrm{Y}$ & $\mathrm{Y}$ & $\mathrm{N}$ & $\mathrm{Y}$ & $\mathrm{N}$ \\
\hline Rha 2013 & N/A & $\mathrm{N}$ & $\mathrm{N}$ & $\mathrm{N}$ & $\mathrm{N}$ & $\mathrm{N}$ & $\mathrm{N}$ & $\mathrm{N}$ & $\mathrm{N}$ & $\mathrm{N}$ & $\mathrm{N}$ & $\mathrm{N}$ & $\mathrm{Y}$ \\
\hline Antuna 2013 & N/A & $\mathrm{N}$ & $\mathrm{N}$ & $\mathrm{N}$ & $\mathrm{N}$ & $\mathrm{N}$ & $\mathrm{N}$ & $\mathrm{N}$ & $\mathrm{N}$ & $\mathrm{N}$ & $\mathrm{N}$ & $\mathrm{N}$ & $\mathrm{N}$ \\
\hline Kesikburun 2013 & N/A & $\mathrm{N}$ & $\mathrm{N}$ & $\mathrm{N}$ & $\mathrm{N}$ & $\mathrm{N}$ & $\mathrm{N}$ & $\mathrm{N}$ & $\mathrm{N}$ & $\mathrm{Y}$ & $\mathrm{N}$ & $\mathrm{N}$ & $\mathrm{Y}$ \\
\hline Zumstein 2014 & N/A & N/A & $\mathrm{N}$ & $\mathrm{N}$ & $\mathrm{N}$ & $\mathrm{N}$ & $\mathrm{N}$ & $\mathrm{N}$ & $\mathrm{N}$ & $\mathrm{N}$ & $\mathrm{N}$ & $\mathrm{Y}$ & $\mathrm{Y}$ \\
\hline Hak 2014 & N/A & N/A & $\mathrm{N}$ & $\mathrm{N}$ & $\mathrm{N}$ & $\mathrm{N}$ & $\mathrm{N}$ & $\mathrm{N}$ & $\mathrm{N}$ & $\mathrm{Y}$ & $\mathrm{N}$ & $\mathrm{Y}$ & $\mathrm{N}$ \\
\hline Jo 2015 & N/A & N/A & N/A & N/A & $\mathrm{N}$ & $\mathrm{N}$ & $\mathrm{N}$ & $\mathrm{N}$ & $\mathrm{N}$ & $\mathrm{Y}$ & $\mathrm{Y}$ & $\mathrm{Y}$ & $\mathrm{Y}$ \\
\hline Pandey 2016 & N/A & N/A & N/A & N/A & N/A & N/A & N/A & N/A & $\mathrm{N}$ & $\mathrm{N}$ & $\mathrm{Y}$ & $\mathrm{Y}$ & $\mathrm{Y}$ \\
\hline D'Ambrosi 2016 & N/A & N/A & N/A & N/A & N/A & N/A & N/A & N/A & $\mathrm{N}$ & $\mathrm{N}$ & $\mathrm{N}$ & $\mathrm{Y}$ & $\mathrm{Y}$ \\
\hline Holtby 2016 & N/A & N/A & N/A & N/A & N/A & N/A & N/A & N/A & $\mathrm{N}$ & $\mathrm{N}$ & $\mathrm{Y}$ & $\mathrm{Y}$ & $\mathrm{N}$ \\
\hline Ebert 2017 & N/A & N/A & N/A & N/A & N/A & N/A & N/A & N/A & N/A & $\mathrm{N}$ & $\mathrm{N}$ & $\mathrm{N}$ & $\mathrm{Y}$ \\
\hline Flury 2017 & N/A & N/A & N/A & N/A & N/A & N/A & N/A & N/A & N/A & $\mathrm{N}$ & $\mathrm{N}$ & $\mathrm{Y}$ & Y \\
\hline Malavolta 2018 & N/A & N/A & N/A & N/A & N/A & N/A & N/A & N/A & N/A & $\mathrm{N} / \mathrm{A}$ & $\mathrm{N}$ & $\mathrm{N}$ & $\mathrm{N}$ \\
\hline Walsh 2018 & N/A & N/A & N/A & N/A & N/A & N/A & N/A & N/A & N/A & N/A & $\mathrm{N}$ & $\mathrm{N}$ & $\mathrm{N}$ \\
\hline
\end{tabular}


Table 5. Scoring to Evaluate the Quality of the MetaAnalysis

\begin{tabular}{lcc}
\hline Author & Oxman-Guyatt & PRISMA Score \\
\hline Chahal & 9 & 24 \\
Zhang & 9 & 27 \\
Moraes & 9 & 27 \\
Li & 9 & 27 \\
Zhao & 9 & 27 \\
Warth & 9 & 27 \\
Vavken & 9 & 27 \\
Cai & 9 & 27 \\
Yang & 9 & 27 \\
Fu & 9 & 27 \\
Han & 9 & 27 \\
Hurley & 9 & 27 \\
Chen & 9 & 27 \\
\hline
\end{tabular}

The Oxman-Guyatt score evaluates the quality of evidence of the meta-analysis using a series of 10 questions-the closer to 10-the higher the quality. The PRISMA score is a checklist evaluation of the quality of steps taken in each individual meta-analysis.

CINAHL. Moreas et al. ${ }^{20}$ were the only ones to use LILACS. Li et al. ${ }^{12}$ were the only ones to use Biosis. Early studies used a mixture of randomized and nonrandomized studies. Studies after 2015 used only randomized controlled trials. This is likely to have occurred, as there were a lack of randomized controlled trials before 2015 .

\section{Studies Employed}

A number of the earlier meta-analyses involved nonrandomized controlled trials in their studies. Chahal et al. ${ }^{10}$ and Vavken et al. ${ }^{16}$ are a few examples. However, with the increasing number of randomized controlled trials available, this practice has been stopped by recent meta-analyses. It should be noted that although the majority of articles are captured by each relevant meta-analyses, some of the articles are missing. This may be due to the heterogeneity in scoring systems used among trials making certain trials inert in the analysis.

\section{Study Quality and Validity}

All of the articles were scored by the PRISMA and Oxman-Guyatt, similar to Saltzmann et al.'s ${ }^{6}$ usage in their previous work. Saltzman et al. used the QUORUM score, which has now been superseded by the PRISMA score. All of the studies obtained high scores, scoring between 24 and 27. All studies were scored by the Oxman-Guyatt score of 9, which indicates the meta-analysis was of high quality (Table 5). These studies noted in many of the randomized controlled trials that there was a high risk of bias in certain studies.

\section{Risk of Bias}

Li et al. and Zhao et al. noted a low to medium risk of bias. Warth et al. ${ }^{13}$ undertook a detailed analysis

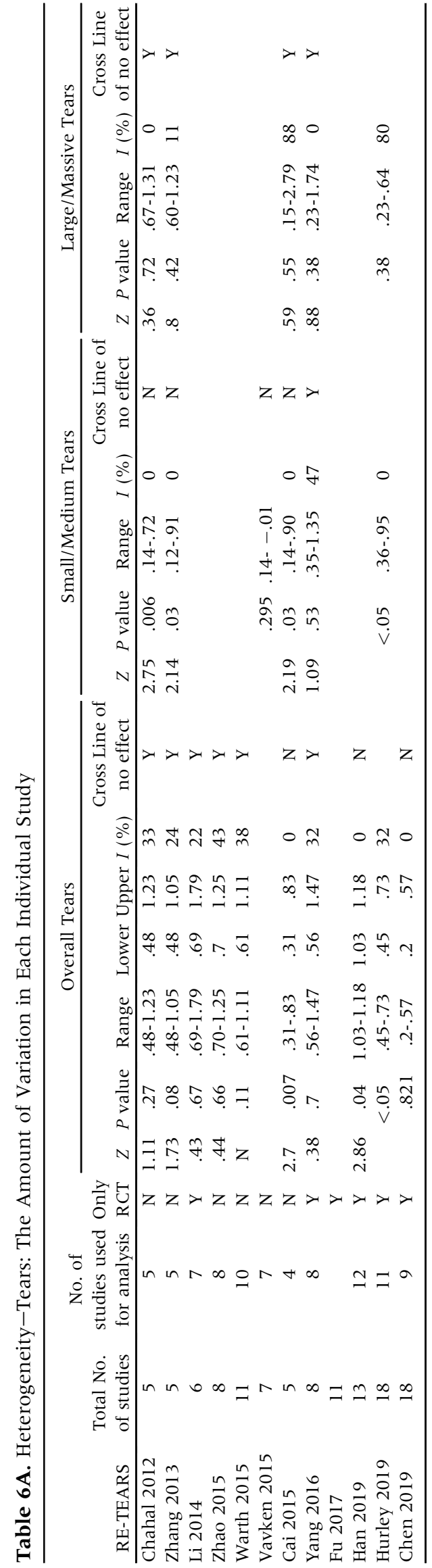


Table 6B. Clinical Outcomes

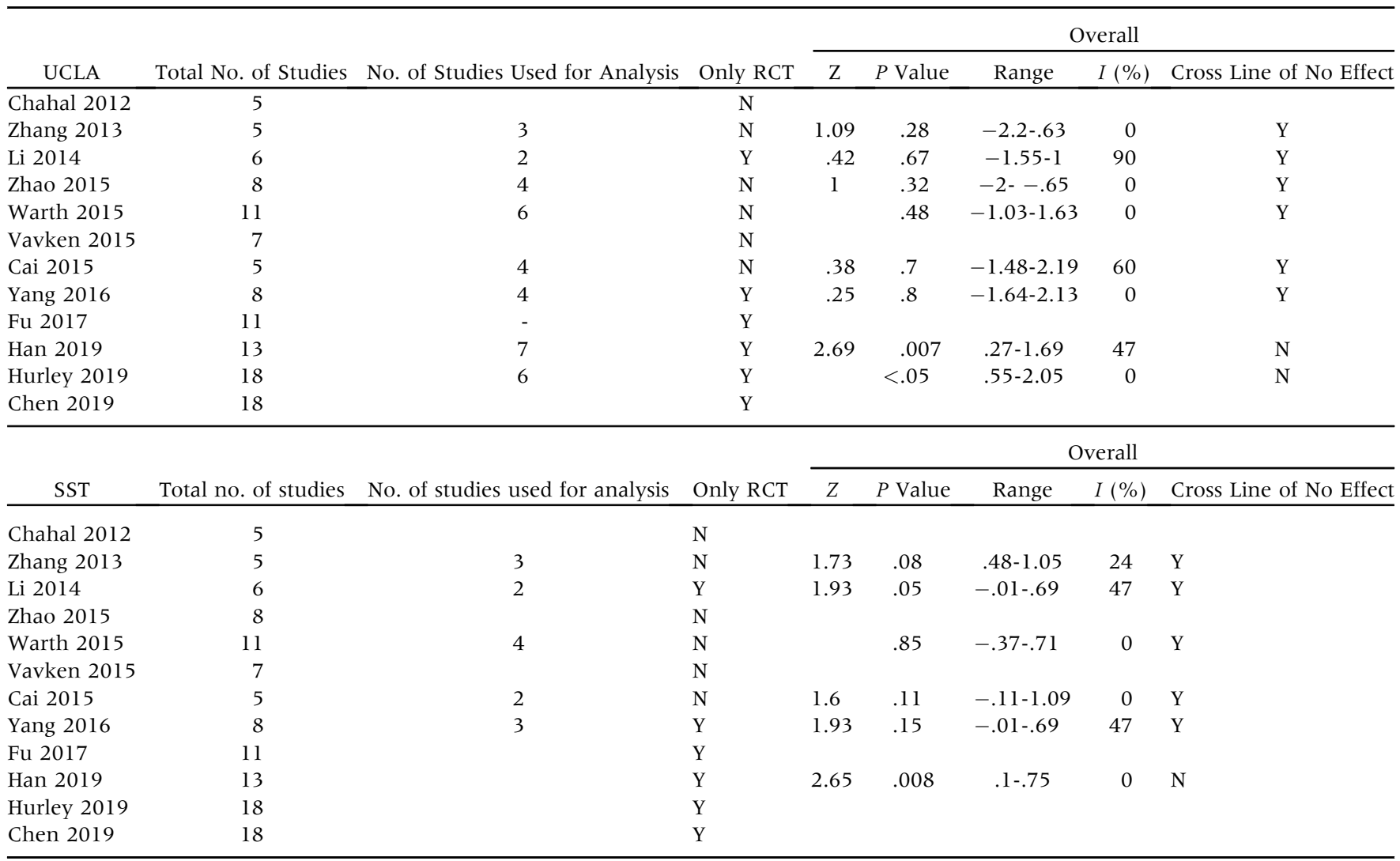

noting 5 out of 11 studies had a high risk of selection bias. They also noted that 6 out of 11 studies had a performance bias. Cai et al., ${ }^{21}$ Yang et al., ${ }^{22}$ and $\mathrm{Fu}$ et al. ${ }^{23}$ found a low risk of bias. Hurley et al. ${ }^{19}$ undertook a Jaddad score ${ }^{9}$ of $3.8 \pm .7$, suggesting an overall high quality of study but noted that 3 out of the 18 studies had a high risk of bias.

\section{Heterogeneity and Subgroup Analyses}

The majority of the meta-analysis undertook $I$ squared tests for clinical and radiological outcomes. The issue with heterogeneity is that the outcomes were recorded with a variety of scoring methods and that these were not universally employed. Seven studies undertook $I$ squared tests for retears. Earlier studies, including $\mathrm{Li}$ et al. ${ }^{12}$ and Warth et al. ${ }^{13}$ both found moderate heterogeneity. Zhang et al. ${ }^{24}$ decided to undertake a subgroup analysis by tear size, and as a result, were the first to find PRP effective for small and medium tears with low heterogeneity. Articles by Vavken et al. ${ }^{16}$ and Cai et al. $^{21}$ echoed this. Recent studies included Hurley et al. ${ }^{19}$ and Chen et al. ${ }^{11}$ found PRP effective for reducing retears in all types of tears.

Only Chen et al. ${ }^{11}$ and Hurley et al. ${ }^{19}$ looked at leukocyte concentration in PRP. Chen et al. ${ }^{11}$ undertook a subgroup analysis for leukocyte content and gel application (thickened with coagulants), showing low heterogeneity for both, and these were not factors in determining the effectiveness of PRP to reduce retear rates. Leukocyte content and commercial brand was not shown to make any impact on outcome. ${ }^{19}$

The VAS pain analysis showed a low heterogeneity; again, only the later studies would show PRP of benefit over the control. Hurley et al. ${ }^{19}$ undertook a subgroup analysis analyzing VAS score at different time periods, showing both had low heterogeneity and that PRP was effective in reducing pain scores. Chen et al. ${ }^{11}$ showed PRP was effective for the short term, but not in the long term. Subgroup analysis with low heterogeneity at leukocyte content and gel application led to no difference in the results.

The Constant score had low heterogeneity in the majority of studies. This is not surprising, as these are the most common scores employed in clinical studies. Warth et al. ${ }^{13}$ undertook a subgroup analysis of Constant scores. They undertook subgroup analysis of levels of evidence; tear size, fixation method, PRP preparation PRP application, and PRP consistency. Despite this, they found a difference between the treatment groups. They employed a Leave-One-Out analysis for ASES (American Shoulder and Elbow Surgeons), UCLA (University of California, Los Angeles), Constant, Simple Shoulder Test (SST), VAS (visual analog scale) pain scores, again concluding no difference. A recent paper by Hurley 
Table 6C. Overall Recommendation for PRP

\begin{tabular}{|c|c|c|c|}
\hline Studies & Retears & Clinical & Comment \\
\hline Chahal 2012 & $\mathrm{~N}$ & $\mathrm{~N}$ & $\begin{array}{l}\text { Small study size. Only } 5 \text { studies } \\
\text { reviewed of which only } 2 \\
\text { randomized. Study is too small for } \\
\text { quantitative synthesis undertaken. }\end{array}$ \\
\hline Zhang 2013 & $\mathrm{~N}$ & $\mathrm{~N}$ & $\begin{array}{l}7 \text { studies reviewed of which } 3 \text { were } \\
\text { randomized controlled trial. } \\
\text { Insufficient numbers appropriate } \\
\text { for meta-analysis. }\end{array}$ \\
\hline Li 2014 & $\mathrm{~N}$ & $\mathrm{~N}$ & $\begin{array}{l}7 \text { studies reviewed of which only } 4 \\
\text { were randomized trials. Insufficient } \\
\text { evidence to make a conclusion }\end{array}$ \\
\hline Zhao 2015 & $\mathrm{~N}$ & $\mathrm{~N}$ & $\begin{array}{l}8 \text { studies reviewed, all randomized } \\
\text { controlled trials. Patient number } \\
\text { was low (under } 500 \text { patients). }\end{array}$ \\
\hline Warth 2015 & $\mathrm{~N}$ & $\mathrm{~N}$ & $\begin{array}{l}11 \text { studies reviewed of which } 8 \text { were } \\
\text { randomized. They did note } \\
\text { improvement of Constant scores } \\
\text { and retear rates of PRP, but that } \\
\text { was statistically significant at this } \\
\text { point. }\end{array}$ \\
\hline Vavken 2015 & $\mathrm{~N}$ & $\mathrm{~N}$ & $\begin{array}{l}13 \text { studies. Effective for small and } \\
\text { medium tears. }\end{array}$ \\
\hline Cai 2015 & $\mathrm{Y}$ & $\mathrm{N}$ & $\begin{array}{l}5 \text { studies were reviewed, which } \\
\text { showed a reduce retear rate in } \\
\text { small- to moderate-sized tears }\end{array}$ \\
\hline Yang 2016 & $\mathrm{~N}$ & Y & $\begin{array}{l}8 \text { studies reviewed. Noted } \\
\text { improvement in postoperative pain } \\
\text { but not in retear rate. }\end{array}$ \\
\hline Fu 2017 & N/A & $\mathrm{N}$ & $\begin{array}{l}11 \text { studies reviewed. Did not look at } \\
\text { retears. No clinical improvements } \\
\text { noted. }\end{array}$ \\
\hline Han 2019 & $\mathrm{Y}$ & Y & $\begin{array}{l}13 \text { studies showed improvement in } \\
\text { pain, function, and retear rates. }\end{array}$ \\
\hline Hurley 2019 & $\mathrm{Y}$ & Y & $\begin{array}{l}18 \text { studies showed improvement in } \\
\text { pain, function, and retear rates. }\end{array}$ \\
\hline Chen 2019 & $\mathrm{Y}$ & Y & $\begin{array}{l}18 \text { studies showed improvement in } \\
\text { retear rate and functional } \\
\text { outcomes. }\end{array}$ \\
\hline
\end{tabular}

et al. ${ }^{19}$ and Chen et al. ${ }^{11}$ showed that PRP was effective in improving Constant scores. Chen et al. ${ }^{11}$ showed in subgroup analysis with low heterogeneity that despite the leukocyte content and gel application method, PRP improved Constant scores over control.

Eight studies looked at the UCLA scores. Li et al. ${ }^{12}$ noted high heterogeneity for the UCLA scores, where the majority noted low to moderate. The issue with the UCLA score is that few of the randomized controlled trials utilized it. The SST score was noted as low-tomoderate heterogeneity. The ASES and the SST score, though used less frequently, also noted low-tomoderate heterogeneity.

Overall, the data are suggestive of low-to-moderate heterogeneity, which suggests that the data are comparable. This strengthens the conclusions of these articles, though it should be noted that this changed with time,

\section{Overall Recommendations}

Early studies did not recommend PRP for clinical or radiological benefit (See Table 6B and 6C). Warth et al. ${ }^{13}$ first noted in 2015 of possible reduced retear and Constant score, but it was not statistically significant. Following this Vavken et al. ${ }^{16}$ and Cai et al. ${ }^{21}$ noted a statistically significant improvement of retear rate in small and medium retears. The four meta-analyses that were recently published all now show a clinical and radiological benefit of PRP over control. The reasons are potential improvement in technology of PRP production, application (improved retear rates with bone-tendon implementation), and larger number of patients that results in adequate power that allows the detection of effect of PRP. Also, the previous metaanalyses had small numbers and fewer randomized controlled trials, and they used nonrandomized controlled trials. Strict meta-analysis rules do not advise or allow it.

\section{Jaddad Decision Algorithm}

Four of the authors applied the Jaddad methodology 9 to identify which of the studies provided the strongest evidence. After analysis, it was determined 11 out of 13 studies delivered high-quality evidence, including Jaddad scores, ${ }^{9}$ Detsky scores, ${ }^{25}$ and appropriate subgroup analysis. The current evidence suggests that PRP reduces the rate of retear, can reduce short-term pain, and provides better functional outcomes as compared to control. This is despite the tear size or the leukocyte content. It has been found that the application of PRP at the tendon-bone interface provides the most benefit, whether a gel is employed or not.

\section{Discussion}

In our study, PRP augmentation for arthroscopic rotator cuff tear led to lower retear rates and improved short-term postoperative functional outcome scores

We critically analyzed 13 studies, of which 6 were level I, 6 were level II and 1 was level III. These studies were deemed of high quality after analysis with PRISMA and Oxman-Guyatt scores, lending credence to their findings. There is a conflict of conclusions between early and later studies, the effectiveness of PRP only being shown in later articles. The resolution of this conflict is apparent from our study, with a subgroup analysis of later meta-analyses showing that with appropriate numbers, PRP is effective in improving functional outcome, as well as the rate-of retear. Certain factors such as gel application and high numbers of leukocytes have shown no difference to the effectiveness of PRP, but the application at the tendonbone interface was superior to the application over the repair site.

According to our findings, platelet-rich plasma is recommended for augmenting rotator cuff repair. PRP 
preparation, application, and consistency do not seem to affect outcomes. This finding is in contrast to Saltzman et al., ${ }^{6}$ who also conducted a systematic review of meta-analyses in May 2016. The effect of PRP application timing (before and after repair) could not be commented on, as the large majority did the application after repair, as the PRP could affect the surgical visualization.

Saltzmann et al. ${ }^{6}$ only included 7 meta-analyses, of which six were level of evidence II and one was level of evidence II. Out of the 7 studies, only one by Li et al. ${ }^{12}$ looked exclusively at randomized controlled trials, the others included cohort studies, lowering the quality of data produced. The most recent meta-analysis reviewed by Saltzmann et al. ${ }^{6}$ was Vavken et al. ${ }^{16}$ from 2015, which looked only at 11 studies, of which only 8 were randomized.

They undertook an analysis of these 7 studies and scored them according to Oxman-Guyatt and QUORUM. They found that looking at re-tear rates, Constant, UCLA, ASES, and SST there was no difference between PRP-treated groups and controls. However, they did note the trend in their subgroup analysis findings, suggesting small-to-moderate tears, and using PRP in the tendon-bone interface had improved outcomes.

In contrast, our study looked at 13 meta-analyses, the latest being published in 2019. These studies included 6 level I, 6 level II, and 1 level III. The last meta-analysis of our study looked at 18 randomized controlled trials.

Our study differs from Saltzman et al. ${ }^{6}$ due to the fact we had a number of higher-quality studies available to us. We also had a larger number of patients. This suggests that with an adequately powered data, the clinical and radiological benefit can be seen in the use of PRP.

The meta-analyses presented have limitations. Aside from the six level I studies, we included one level II and six level III studies. As a result, there may be bias, including selection and publication bias. These studies included low-to-moderate heterogeneity. The other issue is that the preparation and application are so variable that it can be difficult to compare. Subgroup analysis did not show any differences; however, these subgroup analyses had a limited number of studies. The employment of scoring systems still varies between studies, so a limited comparison could be made. Also, there is no standardization of surgical technique, including the use of acromioplasty, the method of repair, and the postoperative physiotherapy.

Even if PRP does have some positive effect, the issue of how substantial and whether this is cost-effective needs to be seen. Vavken et al., ${ }^{16}$ who undertook a meta-analysis in March 2015 of 13 studies, of which only 7 were randomized controlled trials, suggested that PRP is not cost-effective. Making a costeffectiveness statement of PRP at this early stage is presumptuous. Early adopters of new treatments will always be expensive in the short term. However, as the treatment evolves and the use becomes more widespread through an economy of scales, the treatment will be substantially less costly. With a better technique in hand, PRP has the potential to be cost-effective and prevent the need for further surgery. This reduction in morbidity may also lead to more economic benefits for society as a whole.

\section{Limitations}

The majority of the meta-analyses unfortunately included low-level evidence. If we did not include them, we would be essentially missing half of published meta-analyses in the literature. Also, a large proportion of current thinking of PRP was based on these early reviews. Including these studies to address their weaknesses is important to help clinicians understand why prevalent thinking is incorrect and how more powerful recent studies of higher-quality data has led to a different understanding. However, as a result, this creates limitation in our analysis.

Another limitation is that we are reviewing metaanalyses, not individual randomized controlled trials. We are depending on the findings of the group who wrote the article. The information extracted from the article could be incorrect due to method or human error. By analyzing the conclusions of other groups, we create another level of error, based on the distance from the actual evidence. We do our best to minimize this by undertaking stringent criteria to evaluate each article.

\section{Conclusion}

Our study shows that PRP is effective in reducing retears after rotator cuff repair and improving functional outcome scores and reducing short-term pain.

\section{References}

1. Wani Z, Abdullah M, Habeebullah A, et al. Rotator cuff tears: Review of epidemiology, clinical assessment and operative treatment. Trauma 2016;18:190-204.

2. Ahmad Z, Parkar A, Shepherd J. Revolving doors of tendinopathy: definition, pathogenesis and treatment. Postgrad Med J 2020;96:94-101.

3. Ahmad Z, Al-Wattar Z, Rushton N, et al. Holding on by a thread: the continuing story of rotator cuff tears. Br J Hosp Med (Lond) 2021;82:1-10.

4. Ahmad Z, Howard D, Brookset RA, et al. The role of platelet rich plasma in musculoskeletal science. JRSM Short Rep 2012;3:40.

5. Ahmad Z, Brooks R, Kang S-N, et al. The effect of plateletrich plasma on clinical outcomes in lateral epicondylitis. Arthroscopy 2013;29:1851-1862.

6. Saltzman BM, Jain A, Campbellet KA, et al. Does the use of platelet-rich plasma at the time of surgery improve clinical outcomes in arthroscopic rotator cuff repair when 
compared with control cohorts? A systematic review of meta-analyses. Arthroscopy 2016;32:906-918.

7. Liberati A, Altman DG, Tetzlaff J, et al. The PRISMA statement for reporting systematic reviews and metaanalyses of studies that evaluate healthcare interventions: explanation and elaboration. BMJ 2009;339: b2700.

8. Oxman AD, Guyatt GH. Validation of an index of the quality of review articles. J Clin Epidemiol 1991;44: $1271-1278$.

9. Jadad AR, Haynes RB, Hunt D, Browman GP, et al. The Internet and evidence-based decision-making: a needed synergy for efficient knowledge management in health care. CMAJ 2000;162:362-365.

10. Chahal J, Van Thiel GS, Mall N, et al. The role of plateletrich plasma in arthroscopic rotator cuff repair: A systematic review with quantitative synthesis. Arthroscopy 2012;28:1718-1727.

11. Chen X, Jones IA, Togashi R, Park C, Vangsness CT Jr, et al. Use of platelet-rich plasma for the improvement of pain and function in rotator cuff tears: A systematic review and meta-analysis with bias assessment. Am J Sports Med 2019;48:2028-2041.

12. Li X, Xu C-P, Hou Y-L, Song J-Q, Cui Z, Yu B, et al. Are platelet concentrates an ideal biomaterial for arthroscopic rotator cuff repair? A meta-analysis of randomized controlled trials. Arthroscopy 2014;30:1483-1490.

13. Warth RJ, Dornan GJ, James EW, Horan MP, Millett PJ. Clinical and structural outcomes after arthroscopic repair of full-thickness rotator cuff tears with and without platelet-rich product supplementation: A meta-analysis and meta-regression. Arthroscopy 2015;31:306-320.

14. Zhao JG, Wang ZL, Zhao L. Platelet-rich plasma in arthroscopic rotator cuff repair. Arthroscopy 2015;31:9-10.

15. Zhang Q, Ge H, Zhou J, Cheng B, et al. Are platelet-rich products necessary during the arthroscopic repair of fullthickness rotator cuff tears: A meta-analysis. PLoS One 2013;8:e69731.
16. Vavken P, Sadoghi P, Palmer M, et al. Platelet-rich plasma reduces retear rates after arthroscopic repair of small- and medium-sized rotator cuff tears but is not cost-effective. Am J Sports Med 2015;43:3071-3076.

17. Zhao JG, Zhao L, Jiang Y-X, Wang Z-L, Wang J, Zhang P, et al. Platelet-rich plasma in arthroscopic rotator cuff repair: A meta-analysis of randomized controlled trials. Arthroscopy 2015;31:125-135.

18. Han C, Na Y, Zhu Y, et al. Is platelet-rich plasma an ideal biomaterial for arthroscopic rotator cuff repair? A systematic review and meta-analysis of randomized controlled trials. J Orthopaed Surg Res 2019;14:183.

19. Hurley ET, Lim Fat D, Moran CH, Mullett H. The efficacy of platelet-rich plasma and platelet-rich fibrin in arthroscopic rotator cuff repair: A meta-analysis of randomized controlled trials. Am J Sports Med 2019;47:753-761.

20. Moraes VY, Lenza M, Tamaoki MJ, Faloppa F, Belloti JC, et al. Platelet-rich therapies for musculoskeletal soft tissue injuries. Cochrane Database Syst Rev 2013;12:Cd010071.

21. Cai YZ, Zhang C, Lin XJ. Efficacy of platelet-rich plasma in arthroscopic repair of full-thickness rotator cuff tears: A meta-analysis. J Shoulder Elbow Surg 2015;24:1852-1859.

22. Yang J, Sun Y, Xu P, Cheng B. Can patients get better clinical outcomes by using PRP in rotator cuff repair: A meta-analysis of randomized controlled trials. J Sports Med Phys Fitness 2016;56:1359-1367.

23. Fu CJ, Sun J-B, Bi Z-G, Wang X-M, Yang C-Y. Evaluation of platelet-rich plasma and fibrin matrix to assist in healing and repair of rotator cuff injuries: A systematic review and meta-analysis. Clin Rehabil 2017;31:158-172.

24. Zhang Z, Wang Y, Sun J. The effect of platelet-rich plasma on arthroscopic double-row rotator cuff repair: A clinical study with 12-month follow-up. Acta Orthop Traumatol Turc 2016;50:191-197.

25. Detsky AS, Naylor CD, O'Rourke K, McGeer AJ, L'Abbé KA. Incorporating variations in the quality of individual randomized trials into meta-analysis. J Clin Epidemiol 1992;45:255-265. 


\section{Appendix 1}

Terminology used for search:

Tendon, rotator cuff, supraspinatus, infraspinatus, platelet, platelet-rich plasma, PRP, shoulder, subscapularis, external rotators, and platelet concentrate.

\section{Commercial names searched:}

GPS II (Biomet Biologics, Warsaw, IN)

Cascade (MTF, Edison, NJ)

Regenkit; Regen Lab, Switzerland

Haemonetics MC+ (Haemonetics Corp.)

GPS III Platelet concentration system (Biomet Biologics, Warsaw, IN)

PRGF System 1, (BTI Biotechnology, Spain)

PRF Process, Nice, France

Cobe spectra LRS Turbo, Caridian BCT, Lakewood, $\mathrm{CO}$

Vivostat PRF, Alleroed, Denmark

ACP Arthrex (USA)

Harvest Smartprep (Harvest, Plymouth, MA)

Terumo Penpol (Teromo, Japan)

ACP Arthrex (USA) 